\title{
SANGUE MENSTRUAL NA SOCIEDADE KARIPUNA DO AMAPÁ, BRASIL
}

\author{
Ana Manoela Primo dos Santos Soares (D)
}


Este artigo foi elaborado por uma mulher indígena, pertencente ao povo Karipuna do Amapá e com formação na área de antropologia, onde atua em pesquisas colaborativas com as mulheres de seu povo. O texto trata sobre como o djispoze (menstruação) molda as tx ifam Karipuna (meninas) em jonfi e fam (moças e mulheres), assim como tal fluido pode interferir em aspectos do cotidiano das fam, discutindo, ainda, os cuidados que devem ser observados, os perigos que ele pode proporcionar e as relações entre humanos e não humanos e de parentesco que o sangue menstrual gera.

Palavras-chave: Karipuna do Amapá; mulheres indígenas; gênero;

\section{sangue menstrual; relações entre humanos e não humanos}

\section{MENSTRUAL BLOOD IN THE KARIPUNA SOCIETY OF AMAPÁ, BRAZIL}

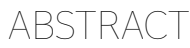

This article was written by an indigenous woman, belonging to the Karipuna people of Amapá and specialized in anthropology, working in collaborative research with the women of her people. The text discusses how djispoze (menstruation) shapes the Karipuna $t x$ ifam (girls) into jonfi and fam (young and women), as well as how such fluid can interfere with aspects of fam's daily life, and it also discusses the precautions that must be observed, the dangers it can provide, and the relationships between humans and nonhumans and the kinship that menstrual blood generates.

Keywords: Karipuna of Amapá; indigenous women; gender; menstrual blood;

\section{SANGRE MENSTRUAL EN LA SOCIEDAD KARIPUNA DE AMAPÁ, BRASIL}

\section{RESUMEN}

Este artículo fue elaborado por una mujer indígena perteneciente al pueblo Karipuna de Amapá y formada en el área de antropología, quien realiza investigaciones colaborativas con las mujeres de su pueblo. Este texto trata de cómo djispoze (menstruación) transforma el $t x$ ifam Karipuna (niñas) en jonfi y fam (jovenes y mujeres). También se ocupa de cómo dicho flujo puede interferir en los aspectos de la vida cotidiana de las fam, y discute los cuidados que deben ser tenidos en cuenta, los peligros que representa, las relaciones entre humanos y no humanos y el parentesco que crea la sangre menstrual.

Palabras clave: Karipuna de Amapá; mujeres indigenas; género; sangre menstrual; relaciones entre humanos y no humanos. 


\section{INTRODUÇÃO: ALGUNS ASPECTOS DO POVO KARIPUNA DO AMAPÁ}

Nós, os Karipuna do Amapá1, somos um povo indígena com uma população próxima a 2.920 pessoas ${ }^{2}$. Vivemos em vinte e uma aldeias, localizadas nas Terras Indígenas Uaçá, Galibi e Juminã, situadas no extremo norte do estado do Amapá, no município de Oiapoque, região de fronteira entre o Brasil e a Guiana Francesa, mas também há alguns de nós que habitam em cidades brasileiras como Oiapoque, Macapá, Belém e Brasília, e em cidades da Guiana Francesa, como Saint-Laurent du Maroni, Kourou e Caiena. Nas Terras Indígenas, compartilhamos nosso território com outros três povos: os Palikur (aruak), os Galibi Marworno (karib) e os Galibi Kalinã $(\text { karib })^{4}$. Compomos o grupo "povos indígenas de Oiapoque", com 39 aldeias. Somos cerca de sete mil indígenas (Silva et al. 2017:5). Cabe esclarecer que a autora deste artigo é indígena Karipuna, portanto, em muitos momentos, utilizarei a primeira pessoa, ao menos no que concerne diretamente a nós.

Nós, os Karipuna, somos de origem tupi (Curt Nimuendajú apud Capiberibe 2001:86), porém, de acordo com pesquisas de Expedito Arnaud (1970:2), com o passar do tempo, fomos "nos esquecendo de nossa língua original” ${ }^{5}$ e nos tornamos falantes da língua patuá ${ }^{6}$. Atualmente, além do patuá, nos utilizamos das línguas portuguesa e francesa. Em nossa organização social, nos dividimos em famílias, praticamos casamentos endogâmicos e exogâmicos

1 Os Karipuna do Amapá são um povo indígena que, apesar do nome, não possuem vínculos com o povo Karipuna de Rondônia, pois têm língua, histórico e aspectos culturais distintos.

2 Segundo dados presentes no site do Instituto Socioambiental (ISA 2006), colhidos em 2014 pelo Sistema de Informação da Atenção à Saúde Indígena (SIASI), por meio da Secretaria Especial de Saúde Indígena (SESAI).

3 Referência ao contexto urbano de Oiapoque. Excetuando-se as Terras Indígenas já mencionadas.

4 Os Galibi Kalinã do Brasil também são conhecidos como Galibi do Oiapoque (Capiberibe 2001).

5 Este esquecimento é um termo utilizado pelo próprio Arnaud (1970:2). É uma metáfora que suaviza os processos de colonização português e francês pelo qual passamos, e que extinguiu parte de nossa língua.

6 O patuá pode ser chamado e grafado como patoá, patois, créole ou kheoul. De acordo com Tassinari (2015:68), "seguindo a grafia para línguas indígenas no Brasil, para sua utilização nas escolas indígenas, [a palavra] passou a ser grafada como kheuol”; enquanto Machado (2017:28-52) diz que o "kheuol falado pelos Galibi Marworno e o patuá ou patoá falado pelos Karipuna são a mesma língua, com pequenas diferenças fonéticas entre si, e são variações do crioulo 'negro' falado na Guiana Francesa”, sendo que estes dois povos o adotaram como sua língua usual. Capiberibe (2001:17) define o patuá como um dialeto originário do francês. Porém, Montejo (1988) fala do kheuol "como a língua materna dos índios Karipuna e Galibi Marworno, sendo o patuá falado também na Guiana Francesa”, afirmando, ainda, que "o patuá é uma língua crioula", porém negando que o "kheuol ou patuá seja um dialeto ou uma espécie de francês mal falado, pois, de acordo com esta, o kheuol se constituiu ao longo dos séculos como verdadeira língua indígena" (Montejo 1988:4-5-8). O kheuol ou patuá, no catálogo da Europalia Îndios no Brasil (Karipuna 2011/2012), é definido por Suzana Primo dos Santos, indígena Karipuna, como "uma mistura de francês e dialetos das famílias indígenas da região de Oiapoque”. Contudo, farei referência à língua falada por nós, Karipuna, somente como patuá, por ser este o termo e a grafia mais utilizados por meu povo. 
(em nível de grupo e para além dele, com outros povos indígenas e até com não indígenas), nossa descendência é tanto matrilinear quanto patrilinear, e nossa cosmologia abarca elementos do catolicismo mesclados com aspectos do xamanismo (Arnaud 1970, 1989, 1991; Soares 2018; Tassinari 2003).

Estes dois primeiros parágrafos sobre os aspectos mais gerais de meu povo foram incluídos neste texto para que o leitor se situe, ainda que superficialmente, em relação a algumas de nossas características principais, como a nossa posição geográfica, a interação com outros povos da região, a nossa origem linguística, a organização social e a religião. Como antropóloga etnóloga, creio ser relevante se estabelecer uma apresentação sobre o povo com o qual se propõe dialogar, e esta é a minha sobre o meu povo. Não pretendendo adentrar de modo mais intenso sobre o que já foi dito sobre nós nos dois parágrafos anteriores, eles são apenas para que o leitor tenha uma breve noção de quem somos, porém, agora, fazse imprescindível que passemos às questões a que de fato me proponho discutir. Retorno, daqui por diante, à minha condição de mulher Karipuna.

\section{TX IFAM, JONFIE FAM}

"Tx ifam", "jonfi" e "fam" são palavras que, em patuá, remetem a figuras do gênero feminino: a primeira significa menina; a segunda, moça solteira; e a terceira, mulher casada ou mulher em sentido geral. Porém, ser menina, moça solteira, mulher casada ou simplesmente mulher no povo Karipuna do Amapá não representa a mesma coisa do que ser menina, solteira, casada ou mulher em outros povos, sejam estes indígenas ou não indígenas.

Neste artigo, priorizo a utilização dos termos em língua patuá que denotam o ser feminino Karipuna, ao invés de traduzi-los para o português, pois, como diz Iannini \& Rodrigues (2018), quando se reportam a linguagens distintas, "há aquilo que se traduz, mas há também os intraduzíveis, pois, em uma tradução, há restos e excessos, ganhos e perdas”. Cardoso de Oliveira (1964), por sua vez, em acordo com a realidade indígena, afirma, na introdução de "O índio e o mundo dos brancos", que conceitos expressam realidades ontológicas específicas e definidas.

Em leitura do texto de Lugones (2010), acerca da questão do gênero, a autora nos leva a estarmos atentos à dicotomia homem/mulher, masculino/feminino, como algo que hierarquiza, sendo esta discussão feita em meio aos contextos não indígenas e de relações entre indígenas e não indígenas. Enquanto Karipuna, percebo esta dicotomia homem/mulher e/ou masculino/ feminino na cosmologia de meu povo como algo que existe e que faz parte de nossos conhecimentos, no entanto, é importante estar atento ao fato de que, 
em nosso contexto indígena (o contexto Karipuna), estas dicotomias não recaem necessariamente sobre a mesma hierarquização que ocorre com as sociedades não indígenas, não significando que, entre nós, não hajam hierarquizações da ordem de gênero, principalmente introjetadas pelo mundo dos brancos, e que reproduzem contextos de violência típicos do patriarcalismo.

Todavia, no âmbito cosmológico dentro do qual abordo o masculino e o feminino, esses termos possuem uma outra contextualização. Não posso tratar as mulheres e os homens indígenas Karipuna ou os conceitos de homem e mulher/ masculino e feminino de maneira homogênea ou universalizante. Eles possuem particularidades que são correspondentes apenas a nós, Karipuna. Por conta disso, trato aqui as meninas, as moças e as mulheres como tx ifam, jonfi e fam; já em relação aos homens, como não entro em suas subdivisões, me refiro a eles como om ou $\mathrm{uom}^{7}$.

Ser mulher Karipuna, ou seja, ser fam Karipuna é apenas umas das formas existentes de ser mulher indígena, pois cada povo possui as suas especificidades e, nesta forma, há todo um universo, ou melhor, toda uma cosmologia, todo um conhecimento indígena. Nesse sentido, e aqui retomo Iannini \& Rodrigues (2018) e Cardoso de Oliveira (1964), é necessário privilegiar as particularidades da ontologia e da cosmologia Karipuna, e, como há risco de perdas de ordem linguística e de sentido na explicação dos fatores cosmológicos e sociais que moldam as fam Karipuna, os termos ou conceitos de ser mulher permanecem em minha língua indígena, pois usálos em português seria manter uma lógica que não é a nossa. Nesse sentido, ressalto o que Lugones (2010:943-944) diz: “[...] traduzir no vocabulário de gênero, na concepção dicotômica, heterossexual, racializada e hierárquica que dá significado à distinção de gênero é exercer a colonialidade da linguagem por meio da tradução colonial”.

Neste artigo, trato de uma parte da formação do ser feminino Karipuna correspondente à menstruação, algo que diz respeito às classes de idade das fam, mas que também corresponde às relações entre humanos e não humanos e às questões de parentesco, as quais também serão abordadas. A concepção do corpo da fam Karipuna é diferente da forma como as mulheres não indígenas concebem seus corpos; pode-se dizer que os diversos povos indígenas possuem ideias específicas sobre os corpos, que diferem entre si. Não que os corpos, ao menos sob a égide da fisiologia

$7 \mathrm{Om}$ ou uom são palavras em língua patuá que significam homem, em seu sentido geral, ou marido, homem casado. Esclarecendo que não entro nas subdivisões dos om da mesma maneira como me dedico às subdivisões das fam, pois, a mim, como mulher indígena Karipuna, cabe que eu trate dos aspectos femininos de meu povo, ao invés dos masculinos, adentrando neste segundo universo apenas quando for necessário para a melhor explicação de algo concernente ao feminino Karipuna ou algo que seja ao mesmo tempo concernente ao feminino e ao masculino. 
ocidental, possuam características anatômicas que os tornem diferentes. No entanto, no que concerne à concepção das diversas cosmologias ameríndias, os corpos são distintos anatômica e interpretativamente, o que converge para o fato de que há concepções distintas de corpo que se modificam de acordo com o povo e com a temporalidade na qual se aborda este conceito. Como diz Seeger et al. (1979), “o corpo é imaginado em vários sentidos pela sociedade”.

A fase de ser tx ifam, ou seja, a fase de ser menina, ou a fase de ser criança, entre nós, Karipuna, termina com a primeira menstruação. A menarca simboliza para as tx ifam o princípio da vida adulta, momento da vida que se consolidará definitivamente a partir do momento em que contraírem matrimônio. Logo, em patuá, é mais comum que chamemos as mulheres solteiras como "jonfi" do que como "fam", que, apesar de ser uma palavra para denotar mulher em um sentido geral, é também a palavra que remete à esposa.

Entre nós, Karipuna, não há festas que privilegiem essencialmente a condição do ser feminino, ou seja, rituais de grande porte que demarquem épocas importantes da vida da fam, como a passagem da infância para a vida adulta, a exemplo da festa da Menina Moça que ocorre entre os Tembé Tenetehara e os Guajajará, ou da apresentação da menina como mulher entre os Kaingang (Carvalho 2014). Porém, na cosmologia de meu povo, há elementos como fatores preponderantes para a demarcação de ser fam (mulher), sendo eles, respectivamente, o sangue menstrual e o casamento. Neste artigo, detenho-me mais sobre o primeiro.

\section{EU, MULHER INDÍGENA, E AS PESQUISAS COM MULHERES EM OIAPOQUE}

Cabe esclarecer que, entre as classificações apresentadas, sou uma jonfi, uma moça solteira, porém, por minha idade, que atualmente conta vinte e cinco anos, eu já deveria ser uma fam casada. As mulheres de meu povo geralmente casam-se e tornam-se mães extremamente jovens, em uma faixa etária que, para os não indígenas, é considerada precoce e corresponde à adolescência, mas, para nós, é vista com naturalidade, uma vez que nossa cosmologia declara como aptas ao casamento e a tornarem-se mães as tx ifam que menstruam, tornando-se, em decorrência disso, jonfi, cabendo ao casamento torná-las fam. Todavia, permaneço jonfi e sem filhos, pois a prioridade da qual meus pais me incumbiram foi a de estudar antes de me tornar fam. Hoje, curso o Mestrado em Antropologia, na Universidade Federal do Pará (UFPA), e, anteriormente a ele, me graduei em Ciências Sociais, também pela UFPA. Desenvolvo, desde a graduação, projetos de pesquisa que se voltam para as práticas femininas junto a meu povo. As pesquisas que realizo com 
meus parentes ${ }^{8}$ são, em sua grande maioria, relacionadas à aldeia Santa Isabel, localizada na Terra Indígena Uaçá (Oiapoque, Amapá), que é uma aldeia fundada por meus avós, o senhor Manoel Primo dos Santos, mais conhecido como cacique Côco, que era indígena Karipuna, e pela senhora Maria Delfina dos Santos Batista, que era indígena Karipuna e Palikur ${ }^{9}$, isto nos anos 1940 (Tassinari 2003).

O meu papel de mulher Karipuna que está na universidade é o de estudar para ajudar meu povo naquilo em que meus conhecimentos como antropóloga podem contribuir. O antropólogo indígena Tonico Benites (2015) fala que a posição de "antropólogo indígena é uma conjunção certamente nova para a antropologia brasileira", dizendo também que: "no contexto histórico contemporâneo, os indígenas após estudarem, pesquisarem e se formarem em Antropologia não podem se desvincular tanto de seu povo pesquisado quanto de estudos antropológicos” (Benites 2015).

Uma grande confiança é depositada no antropólogo indígena por ser alguém que, segundo Benites, compreende a história e a luta de seu povo, ao mesmo tempo em que pesquisa em prol das demandas de seu coletivo. Logo, ser antropólogo indígena é assumir uma posição de responsabilidade, pois este é visto como alguém que pode auxiliar na solução dos problemas. O que ele realiza é monitorado tanto por pessoas indígenas quanto por pessoas não indígenas (Benites 2015).

Os povos indígenas de Oiapoque, pela proximidade com a educação institucional através da Licenciatura Intercultural ofertada pela Universidade Federal do Amapá (UNIFAP), no campus de Oiapoque $^{10}$, são muito incentivados a estarem na universidade, tanto por parte dos professores da licenciatura quanto por parte dos próprios indígenas.

Os estudos de gênero com meu povo ainda são bastante incipientes. A mais importante referência de estudos com mulheres Karipuna, assim como também é o mais relevante trabalho sobre tal tema realizado por uma indígena de nosso povo, é a pesquisa de conclusão de curso "As índias vão à luta: a trajetória

8 "Parente" é um termo político que as pessoas indígenas, no Brasil, se utilizam para se referirem a outras pessoas também indígenas, sejam estas oriundas de seu povo ou de algum outro povo indígena.

9 O povo Palikur obedece à descendência patrilinear, embasada no clã ao qual pertence o pai da criança (Capiberibe 2001). Logo, Delfina, apesar de ser por parte de pai Palikur (pois, era filha de Yeopolo Batista, proveniente do clã Wakavunyene, que é o clã da gente do esteio, formiga preta ou formiguinha) (Capiberibe 2001:66), não poderia dar origem a uma descendência de tal povo, por ser mulher e ter se casado com um indígena Karipuna, dando, por conta disso, origem a uma descendência unicamente Karipuna do Amapá, visto que nós, Karipuna, somos matrilineares e patrilineares (Soares 2018; Tassinari 2003).

10 Campus Binacional da Universidade Federal do Amapá (UNIFAP), localizado no município de Oiapoque, no Amapá. 
da Associação das Mulheres Indígenas em Mutirão e sua contribuição para o Movimento Indígena do Baixo Oiapoque", de autoria de Ariana dos Santos (2016), um texto que trata da trajetória da $\mathrm{AMIM}^{11}$, associação das mulheres dos quatro povos de Oiapoque. Esta monografia deu origem a um artigo intitulado "As mulheres no movimento indígena de Oiapoque: uma reflexão a partir da Associação das Mulheres Indígenas em Mutirão" (Santos \& Machado 2019). Outros dois trabalhos que tratam da questão dos gêneros entre os Karipuna são o artigo de Eneida Correa de Assis (2012), “Descobrindo as mulheres indígenas no Uaçá - Oiapoque: uma antropóloga e seu diário de campo", em que a autora trata, sob um viés subjetivo, dos seus primeiros momentos de campo com os povos indígenas de Oiapoque, assim como fala do modo como passou a perceber as mulheres durante as pesquisas; $\mathrm{e} o$ artigo "A organização política das mulheres indígenas do Amapá”, de autoria de três estudantes de história da UNIFAP , que falam sobre a pesquisa de Ariana dos Santos (Silva et al. 2017). Além destes, os únicos trabalhos sobre gênero conosco, sobre os quais tenho conhecimento, são os que realizei nos projetos de iniciação científica de que participei, no trabalho de conclusão de curso e nos de mestrado. Além dessas pesquisas, um primo meu, também Karipuna, relatou a mim que estava a pesquisar sobre a relação das mulheres de nosso povo com as ervas.

Logo, as pesquisas em torno do gênero entre nós, Karipuna, ainda são poucas, mas, algo que é extremamente relevante, é que nós, indígenas, estamos a tomar a frente delas, sendo nós os protagonistas de tal processo. Mas, se por um lado, as pesquisas estão no princípio, por outro, o movimento indígena das mulheres em Oiapoque é extremamente forte e já possui uma longa trajetória.

\section{DJISPOZE: 0 SANGUE MENSTRUAL}

As jonfie as fam Karipuna (meninas e mulheres) possuem concepções e práticas particulares com relação ao sangue menstrual, que, em patuá, se chama djispoze. Ele é um fluido demarcador dos limites do corpo, das fases da vida e dos comportamentos, além de ser considerado uma substância perigosa para as jonfi e fam, se elas se encontram em certas condições e/ou locais. As jonfi e fam menstruadas não podem ir a lugares como rios, lagos, igarapés, olhos d'água, matas, cavernas e roças, pois corre-se o risco de a jonfi ou a fam ser enfeitiçada por algum karuãna ou bicho ${ }^{12}$ que habite o local. Quem menstrua expele uma substância perigosa e deve praticar

11 AMIM significa Associação das Mulheres Indígenas em Mutirão. É a associação das mulheres indígenas de Oiapoque, abarcando as questões das mulheres e dos povos Karipuna, Palikur, Galibi Marworno e Galibi do Oiapoque.

12 De acordo com o livro "Turé dos povos indígenas do Oiapoque” (Andrade 2009:19/51), "Os karuãna ou bichos são pessoas que vivem no Outro Mundo, onde são gente como nós, e que apenas os pajés conseguem ver e se comunicar com eles. Vêm do mar, dos rios, 
reclusões. O sangue menstrual, quando fora do corpo, é atrativo em certos contextos e, em outros, é repulsivo para os encantados. Por vezes, tais seres prejudicam quem produz dito fluido corporal, logo, as jonfie fam, em certas situações, são vistas como "culpadas" por esses seres fazerem mal, ainda que não tenham a intenção de utilizar o djispoze com o fim de causar dano. Portanto, para se evitar tais inconvenientes, as jonfi e fam, quando menstruadas, devem se resguardar e evitar estar em certos lugares que, em outras épocas, podem frequentar sem que haja implicações negativas.

A partir dessas concepções da cosmologia Karipuna, e com base no artigo de Belaunde (2006), é possível interpretar o sangue menstrual, neste contexto, como um elemento poluidor, que, além de possuir um forte odor, impurifica o ambiente quando está fora do corpo. A menstruação, se em contato com karuãnas, pode proporcionar doença (repulsa), morte (repulsa) e rapto (atração) ${ }^{13}$, mas também pode funcionar como um fluido intermediador de uma gestação (atração) (Tabela 1). O referido contato ocorre,
Tabela 1 - Consequências do djispoze na relação entre jonfi e fam Karipuna e os karuãnas.

\begin{tabular}{|c|c|}
\hline Atrativo & Repulsivo \\
\hline Rapto & Doença \\
\hline Gestação & Morte \\
\hline
\end{tabular}

principalmente, por conta do odor que o sangue exala, mas também pelo contato direto com o fluido (Vidal 2007).

Uma jonfi ou fam menstruada que se banha em um rio pode engravidar de um karuãna. Se a fam engravida dos homens no período fértil do mês, também pode engravidar dos karuãnas, porém quando menstruada. Neste caso, o djispoze(fluido menstrual) proporciona uma espécie de fecundação automática, pois não há propriamente intercurso sexual entre a jonfi ou fam e o karuãna; ela só percebe que está grávida desse ser encantado depois de algum tempo, podendo ser ainda durante a gestação ou quando a criança nasce.

Há, ainda, uma segunda forma de a jonfi e a fam engravidarem de algum ser encantado, porém, isso não acontece por vias espontâneas, ocorrendo através do

lagos, das matas e do espaço e são espíritos de aves, cobras, peixes, árvores e estrelas. Os karuãnas que vivem na água são geralmente Cobras Grandes de uma, duas ou até três cabeças e Sereias (Mamã dijlô). Os da floresta são Djab dã bua, como o anão cabeludo Hoho, o Curupira (Yaddeges), a Matintaperera (Maksilili/Mammatki) e Jurupari (Yorokãn). Os que vêm do espaço são considerados grandes médicos e doutores que curam as doenças das pessoas visíveis através dos pajés, como Laposiniê (conhecida em português como Sete Estrelas). Mas os karuãna também provocam doenças e até matam. Há ainda karuãnas que já viveram no nosso mundo, como Yakaikani, e depois se encantaram e viraram Bichos, e outros que gostam de ter filhos com as mulheres visíveis, como a Cobra Kadaikaru e o Jacaré". "[...] Os karuãna ou bichos do mundo invisível são grandes médicos, doutores, cientistas, pessoas como nós que durante o turé são convidadas pelo pajé para participar da festa, tomar muito caxixi e fumar os grandes cigarros de tawari".

13 Como diz Tassinari (2007:18), “[as] etnografias que abordam noções indígenas de saúde e doença vêm mostrando que é recorrente a noção de que as doenças ou a morte são provocadas por atitudes predatórias de entidades cósmicas contra os humanos... Os causadores das doenças podem ser espíritos de mortos, entidades relacionadas aos animais caçados ou a ambientes percorridos, seres sobrenaturais, manipulados ou não por humanos com habilidades de feiticeiros". 
ato sexual da jonfi ou fam com um homem, que em algum momento recente deve ter estado em contato com algum karuãna que o encantou. A criança assim concebida tem como pai o homem e o karuãna. Isto apenas acontece pelo fato de "o homem não ter tomado banho" ou "não ter se lavado direito" (como dizem os Karipuna), após terem estado com um karuãna, para logo em seguida ter ido manter relações sexuais com uma fam. No caso do homem, a água evitaria as consequências do referido contato que, por vezes, nem ele mesmo percebe que ocorreu, pois pode acontecer de ele entrar em contato com um karuãna e não se dar conta disso, seja por consequência de um encantamento ou mesmo porque não percebeu a presença de tal ser.

Para nós, Karipuna, é muito fácil distinguir quando a criança é filha de karuãna ou de homem. Os filhos dos homens são todos saudáveis e nascem sozinhos, ou seja, nasce um bebê por vez, enquanto os filhos que são frutos de karuãnas nascem com problemas de saúde, nascem gêmeos (hohos) ou nascem pajés. Mesmo havendo consciência da distinção entre os filhos que são unicamente dos homens e os filhos que são com karuãnas, os segundos são humanizados por terem nascido com a forma humana, com consciência humana e de mãe humana, e também com um dos pais humano. Ao longo da vida, são socializados, assim como o são os filhos que são apenas dos homens.
As crianças que nascem fracas ou com problemas de saúde muitas vezes morrem cedo. Nesse caso, diz-se que o pai (o karuãna) veio buscar a criança para morar junto dele, desumanizando, assim, o ser por meio da morte, ou seja, levando-o para o Outro Mundo (Mundo dos bichos e karuãnas) ${ }^{14}$. Por meio da morte, a criança deixa de ter a forma humana para tornar-se também karuãna. Segundo relato do pajé Karipuna Raimundo (proveniente da aldeia km 40), citado por Lux Vidal (2007):

Quando a cobra faz um filho, engravida
uma mulher menstruada, que toma
banho no rio, essa cobra (macho) vem
depois pegar esse filho para levá-lo ao
fundo, mas é possível 'conversar'. Se
o filho for batizado, a coisa melhora
bastante. Mas no fim ele vem e pega
mesmo (apud Vidal 2007).

A morte, nestes casos, não representa propriamente o fim da vida: a vida humana se esvai e a personalidade e consciência humana também, mas o ser continua a viver sob a égide de ser bicho ou karuãna, com outra consciência e personalidade que não a humana. Todavia há casos em que a criança não morre, ela cresce e torna-se pajé. Segundo Roque de Barros Laraia (2005:8):

Embora exista uma surpreendente
uniformidade nos procedimentos
dos xamãs, ocorre uma grande
diversidade de explicações para
o surgimento dos mesmos. Em
alguns casos, a explicação é a
hereditariedade, ou seja, somente
podem ser xamãs os descendentes

14 A cosmologia Karipuna do Amapá, de maneira geral, divide o universo em três dimensões: o Mundo dos seres humanos, que é o Mundo dos homens; o Outro Mundo, que é o Mundo dos bichos e karuãnas; e o Mundo dos mortos. 
de um outro. No caso tupiguarani, o fator hereditário não é necessário. Acredita-se que se trata de um dom que deve ser descoberto e desenvolvido através do aprendizado.

Para nós, Karipuna, o xamanismo pode se dar por hereditariedade e por aprendizado, mas principalmente ocorre porque a pessoa é filha de karuãna. No caso dos irmãos gêmeos (hohos), o irmão ou a irmã que nasce após eles é considerado pajé, assim como os gêmeos também o são. Porém, entre meu povo, há diversas formas de ser pajé, podendo-se ser "um pouco pajé" ou um "pajé forte". Mas o que é relevante para a presente discussão é que o período menstrual da jonfi e da fam Karipuna, se for perpassado pelo contato com "sangue menstrual e karuãnas", dá origem a filhos de seres do Outro Mundo e a pajés. Os karuãnas machos insistem em ter filhos com as Karipuna; os mesmos agem como os humanos e sentem vontade de fazer sexo, porém, no Outro Mundo, não há alegria e nem existe o ato sexual, por isso eles fazem filhos com as $\mathrm{fam}^{15}$. Além disso, os karuãnas nem sempre enxergam os humanos enquanto humanos, e muitas vezes os percebem como outros bichos (Vidal 2007). Os karuãnas que mais fazem filhos com as indígenas são as cobras e os jacarés (Andrade 2009).

O caso das crianças doentes e gêmeas é interpretado de maneira variada de acordo com cada povo. Para nós, Karipuna, os gêmeos são a encarnação humana dos hohos, seres encantados das cosmologias dos povos indígenas de Oiapoque, que possuem estatura baixa, são cobertos de cabelo e andam sempre em pares e de mãos dadas, podendo os pares ser compostos por uma fêmea e um macho, duas fêmeas ou dois machos.

Para a fam ter filhos gêmeos, deve, quando menstruada, ter passeado por cavernas, roças ou outros lugares encantados onde havia hohos. Cada casal de hohopossui um cachorro, cujo nome é xen hoho, que, em português, significa "o cachorro do hoho". Assim como os hohos, o xen hohotambém nasce sob a forma humana, sendo ele a primeira irmã ou irmão que nasce logo após os gêmeos. Com saudades, o bicho de estimação vem se juntar aos donos.

De acordo com as pesquisas e com os meus conhecimentos como pessoa Karipuna e como filha de mãe gêmea (ou seja, como descendente direta de hohos, de karuãnas), os dois gêmeos são pajés e a irmã ou irmão que nasce na primeira gestação logo após a dos gêmeos sempre será um xen hoho pajé. De acordo com o cacique e pajé Jakson (comunicação pessoal,

15 De acordo com Vidal (2007), na versão de Galibi Marworno da narrativa sobre o índio Iacaicani, a cobra- fêmea diz a ele: "Aqui (no Outro Mundo) as pessoas não morrem, só quando o mundo mudar... Aqui não tem alegria, as pessoas não fazem sexo, os bichos fazem filhos com as pessoas do Outro Mundo", demonstrando que, para os bichos, o "Outro Mundo" é o mundo dos homens, enquanto que, para nós, indígenas, o "Outro Mundo" é o Mundo dos bichos e karuãnas. 
jan. 2019), da aldeia Santa Isabel, o irmão ou a irmã que é $x e n$ hoho é pajé mais forte do que os gêmeos ${ }^{16}$.

Sobre os filhos de karuãnas, é importante considerar que estes são os representantes de uma das formas de como nós, Karipuna, classificamos algumas das crianças e indivíduos adultos de nosso povo, pois há variadas formas de se compreender as pessoas nos diferentes povos indígenas e até mesmo em um único povo. Estas crianças aparecem como indivíduos “[...] que transitam entre as diferentes esferas cosmológicas, justamente, por não serem totalmente assimiladas à categoria humana" (Tassinari 2007:18). A Tabela 2 resume e organiza as informações presentes no texto sobre os modos como as mulheres Karipuna podem engravidar dos homens e karuãnas.

Retornando à questão dos lugares em que as fam Karipuna não devem estar quando menstruadas, é relevante expor um caso interessante que Estela

Tabela 2 - Modos como as mulheres Karipuna podem engravidar dos homens e karuãnas e outras características dessas gestações.

\begin{tabular}{|c|c|c|}
\hline $\begin{array}{c}\text { Gestação com } \\
\text { homens }\end{array}$ & $\begin{array}{c}\text { Gestação diretamente } \\
\text { proporcionada por bichos } \\
\text { e karuãnas }\end{array}$ & $\begin{array}{c}\text { Gestação proporcionada } \\
\text { por bichos e karuãnas } \\
\text { através do homem }\end{array}$ \\
\hline $\begin{array}{l}\text { Há intercurso } \\
\text { sexual }\end{array}$ & Não há intercurso sexual & Há intercurso sexual \\
\hline $\begin{array}{c}\text { Não há } \\
\text { encantamento }\end{array}$ & Há encantamento & Há encantamento \\
\hline $\begin{array}{l}\text { Crianças saudáveis, } \\
\text { não pajés e que } \\
\text { nascem sozinhas }\end{array}$ & $\begin{array}{l}\text { Crianças doentes, pajés e } \\
\text { gêmeos (hohos) }\end{array}$ & Crianças doentes, pajés e gêmeos (hohos) \\
\hline $\begin{array}{c}\text { Ascendência } \\
\text { paterna humana }\end{array}$ & $\begin{array}{l}\text { Ascendência dupla paterna } \\
\text { (humana e não humana) }\end{array}$ & $\begin{array}{l}\text { Ascendência dupla paterna } \\
\text { (humana e não humana) }\end{array}$ \\
\hline
\end{tabular}

16 Levando-se em consideração todas estas informações, em síntese, compreendo que os gêmeos nascem com o dom para serem pajés e a primeira criança que nasce da mesma mãe logo após eles também terá esse dom. Talvez um gêmeo seja pajé mais forte do que o outro e também mais forte do que o xen hoho, apesar de o xen hoho ter a tendência a ser o mais forte entre todos os irmãos. No caso de minha família, meu tio Vicente, irmão de minha mãe Suzana, era pajé mais forte do que ela e do que o xen hoho dos dois, minha tia Estela, ou seja, seu dom era mais desenvolvido do que o das irmãs. 
Oliveira dos Santos (minha tia, que é xen hoho) narrou sobre minha avó, Dona Delfina. Este acontecimento exemplifica muito bem os cuidados que as mulheres devem ter com o próprio djispoze (sangue menstrual):

Tem uma história que eu conto da minha mãe, né? A minha mãe morava na aldeia Santa Isabel e é meia hora de viagem pra aldeia Manga. Aí um dia ela disse “Ah, mas não tem ninguém aqui então eu vou tomar banho menstruada, vou tomar banho aqui”. Não era rio, mas a água crescia, era um portinho. Ela disse: "Acho que não vai fazer mal nenhum". Aí ela tomou banho. Aí morava um pajé acima do Manga numa aldeia bem no Japim, bem longe, subindo cachoeiras. Aí no outro dia de manhã ele chegou e conversou assim com ela: Nunca mais faça isso! Porque você tá sujando a casa dos bichos e eles não te fizeram nada porque eu não deixei. Então não faça mais isso! E ela nunca mais fez. Ele veio avisar para que não acontecesse nada. Então é isso, a gente, as mulheres têm, pois como que ele soube que ela tava menstruada? Como que ele soube que ela tava naquele local? Então, é nesse sentido. Então, o pajé, ele vê, ele conversa com esses seres do Outro Mundo e eles fazem com que não aconteça o mal para aquelas pessoas (Estela dos Santos Oliveira Karipuna, comunicação pessoal, Belém, 5 dez. 2016).

Esta pequena história demonstra o quanto o descuido com o sangue menstrual e a consequente negligência para com a natureza e os seres que a habitam, gerada por essa atitude, podem vir a ser danosos para as fam e jonfi, assim como reafirma o poder de intermediação e pacificação do pajé. Delfina pensou que, por estar distante dos olhos humanos, ninguém iria lhe descobrir e que, por ser um pequeno ponto de água empoçada, nenhum karuãna habitaria aquele local, portanto, mal nenhum lhe ocorreria.

No entanto, não fosse a intervenção do pajé, muitos poderiam ter sido os malefícios a recair sobre si, a exemplo da narrativa sobre Catarina, fam Karipuna da aldeia Espírito Santo, que quase virou cobra por ter ido mestruada andar de canoa nas proximidades da aldeia Manga:

Um dia uma indígena Karipuna, de nome Catarina, foi acompanhar seu marido em um passeio de canoa, o marido tinha como intenção pescar. Catarina neste dia estava menstruada, e sabia disso, no entanto, mesmo sabendo dos perigos que poderiam lhe acontecer e do azar que poderia proporcionar à pescaria do marido, não mencionou nada sobre o fato. $\mathrm{O}$ marido foi na canoa de costas para a esposa, e após algum tempo dentro dela, percebeu que estava sozinho. Desesperado, começou a chamar por seu nome, mas sem obter respostas foi recorrer ao pajé, que lhe disse que sua esposa estava menstruada e que por conta disso uma cobra a havia levado e a feito de esposa. Agora ambos habitavam o mundo das cobras que ficava logo abaixo do rio Curipi, e onde a própria esposa já se encontrava em processo de transformação. Por uma intervenção do pajé, após três dias o homem conseguiu chegar ao mundo das cobras, onde encontrou a mulher em uma praia acompanhada também de outras cobras que estavam trocando de pele, e onde ela mesma já estava a transformar-se em uma. Sua esposa estava a desumanizarse, estava esquecendo como era ser um ser humano, como era ser uma mulher, suas lembranças estavam esvaindo-se, seu corpo ainda era o de uma pessoa, mas sua pele já estava dando lugar a escamas e estava ficando grudenta como a de uma cobra. O marido humano conseguiu matar o marido cobra, e trazê-la de volta para o mundo dos homens, ao chegar aqui ela recobrou suas memórias e passou a humanizar-se novamente, no entanto, 
sua pele para sempre ficou desse jeito, escamosa e grudenta (Ana Caroline Narciso dos Santos, indígena Karipuna/ Galibi Marworno, minha prima, comunicação pessoal, out. 2016).

Esta história é uma espécie de lição e justificativa cosmológica para as jonfie fam, quando menstruadas, manterem-se afastadas de rios ou outras fontes de água. Elas não podem se aproximar destes lugares, pois estão pondo-se em perigo, além de estarem colocando outros seres humanos e karuãnas também sob tal ameaça. O sangue menstrual (djispoze) é uma substância altamente perigosa e cabe a elas zelarem para que o fluido corporal não venha a thes causar o mal. No caso da história de Catarina, ela tinha conhecimento das consequências deste ato, com relação tanto a si quanto ao marido, que não obteria sucesso na pescaria, e outros fatores surgem como consequência de sua conduta, visto que todas as fam Karipuna são orientadas desde muito jovens, através de narrativas, sobre o que o djispoze pode proporcionar. Catarina foi resgatada por seu marido humano, através da intervenção do pajé Gomes ${ }^{17}$, antes de "virar bicho"; ela recobrou suas memórias e sua consciência humana, mas sua pele continuou, em parte, como a de cobra. Ela voltou a ser humana, a ser fam, no entanto, a consequência deste ato ficou para sempre marcada em sua forma corporal. Como afirmou Tassinari (2007:17), as populações indígenas “associam o ensinamento de valores morais e éticos à produção de corpos saudáveis e bonitos”. Já sobre as cobras, nas cosmologias dos povos indígenas do baixo Oiapoque, Vidal (2007) fala:
A cobra, ainda que invisível, possui força, presença, e uma atração duplamente carnal pelos humanos: alimento e sexo, aspectos sempre reiterados nas narrativas... seu apetite sexual assusta as mulheres, especialmente quando menstruadas.

Segundo Belaunde (2006), as mulheres menstruadas, nas cosmologias indígenas da Amazônia, estão diretamente relacionadas às cobras, pois esses bichos, de tempos em tempos, trocam de pele e reiniciam um novo ciclo. Assim também são as Karipunas jonfi e fam, que de tempos em tempos menstruam e renovam sua condição de seres férteis, geradoras de vida, reiniciando uma nova fase. Portanto, sangue menstrual (djispoze) e peles de cobra assim se correlacionam. Para Laraia (2005), a troca de pele da cobra significa rejuvenescer.

Belaunde (2006) também refere-se à correlação do ciclo menstrual das mulheres com a lua, o que remete à nominação pro lalin, que nós, Karipuna, usamos para nos referirmos ao período menstrual: ao dizermos pro lalin, nós, jonfi e fam Karipuna, estamos literalmente a falar "estou de lua" ou "minha lua", sendo "lalin" uma palavra que, além de lua, significa menstruação.

17 O pajé que aparece na narrativa contada por Estela é, segundo Assis (1981), um pajé que vivia no curso do rio Curipi. 
Com relação à menarca, antigamente as jonfi Karipuna costumavam passar por um período de resguardo chamado repouso. Não podiam ir a determinados lugares e passavam por uma dieta. A dieta acontecia somente na primeira menstruação (djispoze), e consistia em evitar o consumo de carnes de caça consideradas "remosas" ${ }^{18} \mathrm{e}$ de peixes de pele. Hoje em dia, essa dieta foi abandonada, mas permanece o fato de que devem ser evitados rios, lagos, igarapés, olhos d'água, matas, cavernas e roças. Tassinari (2007:17) diz que, entre os povos indígenas, há "listas enormes de alimentos que devem ser ingeridos em certas fases da vida ou em certas circunstâncias e alimentos proibidos para estes momentos”. Eneida de Assis (1981) exemplifica como ocorria a dieta durante a menarca, tratando dos alimentos proibidos e permitidos:

A piranha, por exemplo, está incluída
na categoria dos alimentos proibidos,
porque segundo eles (os Karipuna e os
Galibi Marworno) " $\mathrm{faz}$ arriação, faz a
mulhé tê sangue”. O mesmo critério
é utilizado para determinadas caças
que tenham muito sangue, podendo
provocar as mesmas reações. Quanto
à cutia e certas aves como o inambu
(tinâmidas), estão na categoria dos
alimentos permitidos (Assis 1981:37).

Para os Karipuna, o despertar do desejo sexual feminino é o causador do djispoze, sendo a menarca também uma autorização da natureza para que as recém-jonfi possam se casar.
Atualmente, durante a menarca, as jonfi devem ter cuidados iguais aos que terão em todas as outras djispoze, elas não passam por nenhum ritual específico, todavia, a menstruação possui o diferencial de simbolizar o princípio do desejo sexual e da vida adulta.

\section{0 CASAMENTO CONSOLIDA \\ A FAM COMO ADULTA}

A fam Karipuna possui a liberdade de escolher se deseja se unir a um homem indígena de seu povo, de algum outro povo também indígena ou a um homem não indígena. Espera-se que ela se case com um semelhante, pois pressupõe-se que um companheiro Karipuna, ou de algum outro povo, compartilhará de pontos de vista e de uma sensibilidade para com as questões pertinentes aos nossos conhecimentos e às nossas pautas políticas, que um não indígena talvez não venha a compartilhar. Porém, se ela se casa com um não indígena, a depender de quem seja, isso não significa propriamente um problema, desde que o marido tenha respeito para com o modo de vida Karipuna. E os filhos deste homem não indígena com uma mulher de meu povo serão todos Karipuna, assim como seus netos também o serão, e assim por diante,

18 Expressão muito comum no Norte do Brasil que se refere a certas carnes que fazem mal a determinadas pessoas em condições específicas, adoecendo-as ou piorando um estado de saúde já agravado. Capiberibe (2001) define o conceito de "remoso", em Oiapoque, como os alimentos que são pesados, gordurosos ou perigosos. 
ao longo das gerações. Nossa descendência, independente das combinações, nunca poderá se extinguir, é necessário que apenas um dos pais seja Karipuna para que a criança também o seja, o que constitui uma linha contínua e ininterrupta em nossa descendência. Logo, por mais que nos "misturemos"19, sempre haverá cada vez mais Karipuna e nosso povo, por meio de endogamia e exogamia, cada vez mais será maior e mais forte.

O casamento, para nós, não compreende um rito de festa. Para que ele se consolide, basta que o homem e a mulher passem a morar juntos como marido (om ou uom) e esposa (fam). Para que isso ocorra, é necessário que o homem expresse o desejo de que determinada jonfi Karipuna seja sua fam, dizendo isto aos pais ou outros responsáveis da jovem e levando-a para morar junto dele ou indo morar com a família da jonfi.

A partir de casada, a jonfi passa a ser fam e, ainda que o casamento se dissolva, ela não mais voltará a ser vista como uma moça (jonfi), mas continuará a ser vista como uma mulher (fam). Na organização social Karipuna, o ato de casar-se insere a jonfi no mundo adulto.

\section{CONSIDERAÇÕES FINAIS}

As informações e reflexões contidas neste artigo foram baseadas em uma análise antropológica que, como já mencionado, parte de alguém que é indígena do povo Karipuna. São os escritos de uma indígena sobre alguns aspectos cosmológicos pertinentes às mulheres de seu povo e correspondentes ao sangue menstrual.

Lembro-me de uma vez, quando uma historiadora que trabalha com os povos indígenas de Oiapoque, comentou para mim e minha mãe que ela percebia que muitas questões haviam se transformado em nossa espiritualidade (na espiritualidade Karipuna), mas que ela também observava que as questões correspondentes à cosmologia em torno do sangue menstrual ainda permaneciam fortes. Esse comentário gerou uma espécie de gatilho para mim com relação às pesquisas que já desenvolvia com as mulheres de meu povo, pois constatei o que também já havia percebido ao trabalhar com minhas parentas: muitas das palavras que ouvia das mais antigas ${ }^{20} \mathrm{e}$ que escrevia sobre as narrativas que nos envolviam (nós, mulheres) tinham alguma relação com o fluido e o período menstrual.

O que há neste artigo é uma parte de meu trabalho de conclusão de curso em Ciências Sociais (Soares 2018). O texto se propôs a demonstrar que o djispoze é algo

19 O conceito de mistura é utilizado por meu povo para se referir ao fato de que mantemos uniões de casamento com pessoas de outros povos indígenas e com não indígenas. É uma forma de criticar o discurso dos brancos e de alguns outros povos que apontam estas relações como algo que nos afasta de nossos conhecimentos e de nossas origens indígenas.

20 Modo Karipuna de se referir a mulheres já idosas. 
fundamental para a tx ifam se tornar jonfi e fam, e também a evidenciar alguns dos costumes de reclusão e tabus correspondentes ao período menstrual, que muito aparecem nos discursos das mulheres mais velhas, quando dialogo com elas sobre o modo de vida das fam de nosso povo. O djispoze é algo que molda a menina Karipuna em mulher, estabelecendo uma distinção entre as fases da vida ou das classes de idade, assim como ele aparece como algo que também pode interferir em outras questões da vida das mulheres, como os cuidados que devem ser observados perante este fluido, os perigos proporcionados por ele e as consequências cosmológicas que ele traz. Todavia, também devo esclarecer que estas questões, de forma alguma, colocam o ato de menstruar em uma posição de algo ruim, ou que isso seja algo que inferiorize as jonfie as fam. Não é isso o que ocorre. O djispoze torna os corpos das tx ifam corpos saudáveis de jonfie fam, mediante a adequada administração do fluido menstrual.

O djispoze faz-se presente no que diz respeito às relações entre humanos e não humanos, ou seja, entre as mulheres e os karuãnas, as quais são algo que desencadeia nascimento, morte, parentesco, doença e dom para a pajelança. Utilizo-me de exemplos que rementem à minha mãe, à minha avó materna, a uma tia e a uma prima, para dar molde ao que as relações entre humanos e não humanos representam no âmbito do gênero para meu povo (mas também para meu âmbito familiar). Tratar das mulheres indígenas
Karipuna no que é correspondente à cosmologia em torno do sangue menstrual é, ao mesmo tempo, traçar relações diretas com os karuãnas, portanto, a discussão sobre gênero (mulheres indígenas) e a relação entre humanos e não humanos aparece aqui como algo que se entrelaça e que é inseparável, sendo que eu mesma, como Karipuna e parenta destas mulheres, sou um sujeito e um produto destas relações.

Aqui aparece a relação com a lua, pro lalin; a antiga importância do repouso, que era o resguardo, com a dieta durante a menarca, a qual hoje não mais ocorre; assim como o fato de que o djispoze representa o início de uma vida adulta, e essa vida adulta, para a fam Karipuna, pode ter como outro momento importante a união através de uma relação duradoura, que é o casamento. Não me debrucei, neste texto, sobre as nuances das relações entre om e fam no casamento, pois, apesar de essa etapa ter se apresentado como algo fundamental para a inserção da jonfi na vida adulta, a dimensão simbólica de se tornar fam através dele, no contexto em que discuto, está relacionada à mudança de status que o djispoze pode proporcionar, ou seja, tornar-se famé algo que passa pelos processos de menstruar e casar, mas o próprio casamento só ocorre porque, em algum momento anterior, a menstruação ocorreu primeiro. Os detalhes do casamento e das relações om e fam que há nele são um caminho para outra discussão sobre os papéis da fam dentro desta relação. 
Fiz referência a mim de forma direta no artigo, também para que o leitor tenha conhecimento das posições da qual falo, que são as de mulher indígena, solteira, que atualmente vive em um contexto urbano e participa da vida acadêmica, que gira em torno das pautas e dos conhecimentos dos povos indígenas através da antropologia. Complementando ainda que o território indígena da aldeia Santa Isabel, que é o território de origem dos meus parentes mais próximos, é o espaço fundamental para as pesquisas que desenvolvo com meu povo, portanto, consequentemente também para esta aldeia, pois as descrições aqui presentes foram informadas a mim por minhas parentas provenientes desse local.

Tudo o que há aqui são questões mediadas pelo djispoze e as descrevo porque o povo Karipuna possui muita estima de que os jovens tornem nossos conhecimentos orais e nossas vivências, sempre que possível e permitido, palavras escritas, pois creem que este é um mecanismo importante de conservação dos nossos conhecimentos e das nossas memórias. E é isso também o que realizo com este texto. Através de minha posição de indígena antropóloga, escrevo para um público leitor que abrange, principalmente, as pessoas de meu povo, e estes escritos possuem como principais intenções preservar a memória, as narrativas e os conhecimentos Karipuna, pois "as mais velhas", as “antigas" (ver nota de rodapé 20), desde que iniciei meus estudos em antropologia, sempre me incentivaram a escrever para que o que é Karipuna não se perca ou seja esquecido, mas sim preservado em palavras que agora, para nós, não são apenas as palavras faladas.

\section{REFERÊNCIAS}

Andrade, U. M. (Org.). 2009. Turé dos povos indígenas do Oiapoque. Rio de Janeiro/São Paulo: Museu do Índio/Fundação Nacional do Índio/IEPÉ. Disponível em: https://www.institutoiepe.org.br/media/ livros/livro_ture_povos_oiapoque.pdf. Acesso em: 22 out. 2019.

Arnaud, E. 1970. O xamanismo entre os índios da região Uaçá (Oiapoque - Território do Amapá). Boletim do Museu Paraense Emílio Goeldi, série Antropologia (44):1-26. Disponível em: http://repositorio. museu-goeldi.br/bitstream/mgoeldi/944/1/B\%20MPEG\%20Ant\%20n44\%201970\%20ARNAUD\%20ri. PDF. Acesso em: 25 fev. 2019.

Arnaud, E. 1989. O índio e a expansão nacional. Belém: CEJUP. 
Arnaud, E. 1991. O sobrenatural entre os índios do rio Uaçá (Oiapoque - Amapá) Palikúr, Galibí do Uaçá e Karipúna. Anais da II Reunião de Antropólogos do Norte e Nordeste.

Assis, E. C. 1981. Escola indígena, uma "frente ideológica"? Dissertação de Mestrado, Programa de Pós-Graduação em Antropologia Social, Universidade de Brasília, Brasília.

Assis, E. C. 2012. Descobrindo as mulheres indígenas no Uaçá - Oiapoque: uma antropóloga e seu diário de campo. Papers do NAEA (1):163-180. Disponível em: http://www.generonaamazonia.com/ edicoes/edicao-1/Artigos/Artigo-Descobrindo-as-Mulheres-Indigenas.pdf. Acesso em: 22 out. 2019.

Belaunde, L. 2006. A força dos pensamentos, o fedor do sangue: hematologia e gênero na Amazônia. Revista de Antropologia 49(1):205-243. DOI: http://dx.doi.org/10.1590/S0034-77012006000100007.

Benites, T. 2015. Os antropólogos indígenas desafios e perspectivas. Novos debates. Fórum de Debates em Antropologia 2(1).

Capiberibe, A. M. G. 2001. Os Palikur e o Cristianismo. Dissertação de Mestrado, Instituto de Filosofia e Ciências Humanas, Universidade Estadual de Campinas, Campinas.

Cardoso de Oliveira, R. 1964. O índio e o mundo dos brancos. São Paulo: DIFEL.

Carvalho, J. 2014. Leituras visuais da criança indígena: uma abordagem para além da estética e do racismo étnico em fotografias infantis. Anais do I Encontro de Antropologia Visual da América Amazônica.

Iannini, G. e C. Rodrigues. 2018. Psicanálise entre feminismos e femininos. In Psicanálise entre feminismos e femininos: velhas discórdias novas aproximações. Revista CULT 238:18-19.

Instituto Socioambiental (ISA). 2006. Povos indígenas no Brasil: Karipuna do Amapá. Disponível em: https://pib.socioambiental.org/pt/Povo:Karipuna_do_Amap\%C3\%A1. Acesso em: 10 maio 2019. 
Karipuna, S. P. S. 2011/2012. Calebasse “cuia” Karipuna. In: Índios no Brasil. França. Europalia. Catálogo de exposição.

Laraia, R. B. 2005. As religiões indígenas: o caso tupi-guarani. Revista USP (67):6-13. DOI: https://doi. org/10.11606/issn.2316-9036.v0i67p6-13.

Lugones, M. 2010. Rumo a um feminismo descolonial. Revista Estudos Feministas 22(3):935-952. Disponível em: http://www.scielo.br/pdf/ref/v22n3/13.pdf. Acesso em: 22 out. 2019.

Machado, T. L. 2017. Na cidade vendo a farinha e de lá trago mercadoria e dinheiro para a aldeia: redes de sociabilidades e intercâmbio de bens dos indígenas Palikur na cidade de Oiapoque - AP. Dissertação de Mestrado, Programa de Pós-Graduação em Sociologia e Antropologia, Universidade Federal do Pará, Belém.

Montejo, F. P. 1988. Dicionário Kheuol x Português Português x Kheuol. No Djisone Kheuol - Portixge. O nosso dicionário Português - Kheuol. Povos Karipuna e Galibi Marworno. Edições Mensageiro.

Santos, A. 2016. As índias vão à luta: a trajetória da Associação das Mulheres Indígenas em Mutirão e sua contribuição para o Movimento Indígena do Baixo Oiapoque. Trabalho de Conclusão de Curso, Licenciatura Intercultural Indígena com ênfase em Ciências Humanas, UNIFAP, Oiapoque.

Santos, A., e T. L. Machado. 2019. As mulheres no movimento indígena de Oiapoque: uma reflexão a partir da Associação das Mulheres Indígenas em Mutirão. Espaço Ameríndio 13(1):6786. Disponível em: https://seer.ufrgs.br/EspacoAmerindio/article/view/80987/53109. Acesso em: 22 out. 2019.

Seeger, A., R. DaMatta, e E. Viveiros de Castro, 1979. A construção da pessoa nas sociedades indígenas brasileiras. Boletim do Museu Nacional. Nova Série Antropologia (32):2-19. 
Silva, A. O., J. D. S. A. Costa, e V. S. Esteves. 2017. A organização política das mulheres indígenas do Amapá. Anais do III Encontro de Discentes de História da UNIFAP. Disponível em: https://www2.unifap. br/cepap/files/2017/10/ARIVANETE-VITORIA-E-JONHATA-A-participação-política-das-mulheresindígenas.pdf. Acesso em: 22 out. 2019.

Soares, A. M. P. S. 2018. Mulheres Karipuna do Amapá: trajetórias de vida das Fam-Iela: uma perspectiva autoetnográfica. Trabalho de Conclusão de Curso, Faculdade de Ciências Sociais, Universidade Federal do Pará, Belém.

Tassinari, A. M. I. 2003. No bom da festa. O processo de construção cultural das famílias Karipuna do Amapá. São Paulo: Edusp.

Tassinari, A. M. I. 2007. Concepções indígenas de infância no Brasil. Tellus 7(13):11-25.

Tassinari, A. M. I. 2015. A casa de farinha é a nossa escola: aprendizagem e cognição Galibi Marworno. Revista Política \& Trabalho (43):65-96.

Vidal, L. 2007. A Cobra Grande: uma introdução à cosmologia dos povos indígenas do Uaçá e Baixo Oiapoque - Amapá. Rio de Janeiro: Museu do Índio. 